\title{
Avaliação de silagens de ramas de batata-doce
}

\section{José Altair Figueiredo; Valter C de Andrade Júnior; Rosana Cristina Pereira; Karina G Ribeiro; Daniel José S Viana; Irã P Neiva}

UFVJM, Progr. Pós-graduação em produção vegetal (PPGPV), Campus JK, Rod. MGT 367 km 583, nº 5000, 39100-000 DiamantinaMG; valterjr@ufvjm.edu.br

\section{RESUMO}

O presente trabalho teve como objetivo selecionar clones de batata-doce com potencial para uso na alimentação animal. O experimento foi conduzido em blocos ao acaso, com 11 clones e quatro repetições. Os clones avaliados fazem parte do banco de germoplasma da Universidade Federal dos Vales do Jequitinhonha e Mucuri, sendo: BD-06, BD-25, BD-15, BD-38, Cambraia, BD-31-TO, BD-67, BD-45, BD-42, BD-54 e a cultivar Brazlândia Rosada. Nas ramas coletadas do experimento foram avaliados o teor de matéria seca e as produtividades de massa verde e massa seca. Nas silagens de ramas foram avaliados o $\mathrm{pH}$ e os teores de matéria seca (MS), proteína bruta (PB), fibra em detergente neutro (FDN), fibra em detergente ácido (FDA), nutrientes digestíveis totais (NDT), fósforo, cálcio e sódio. Não houve diferença significativa para a produtividade de massa verde e de massa seca das ramas entre os clones de batata-doce. As silagens produzidas caracterizam-se como volumosos de boa qualidade, apresentando teores satisfatórios de proteína bruta $(11,59 \%)$, FDN $(31,98$ a $39,68 \%)$, FDA $(29,65$ a $35,45 \%)$ e NDT $(62,90$ a $66,91 \%)$, comprovando o potencial de utilização das ramas da batata-doce na forma de silagem.

Palavras-chave: Ipomoea batatas, FDA, FDN, NDT, MS, proteína bruta.

\begin{abstract}
Evaluation of silages of sweet potato vine

The objective of this study was to select potential clones of sweet potato for animal feeding purposes. The experiment was carried out in a randomized block design with four replications. Eleven clones BD-06, BD-25, BD-15, BD-38, Cambraia, BD-31-TO, BD-67, BD45, BD-42, BD-54 and the cultivar Brazlândia Rosada belonging to germplasm bank of the Federal University of Vales do Jequitinhonha and Mucuri (UFVJM) were evaluated. We estimated the dry matter content and the productivity of green and dry mass of the vine. The traits $\mathrm{pH}$, dry matter, crude protein phosphorus, calcium and sodium were estimated in the evaluation of silages quality. There was no significant difference in productivity of green mass and dry mass among the clones of sweet potato. The obtained silages had sufficient levels of crude protein (11.59\%), neutral detergent fiber (31.98 to $39.68 \%$ ), acid detergent fiber (29.65 to $35.45 \%$ ) and total digestible nutrients $(62.90$ to $66.91 \%)$ proving the potential use of the sweet potato vine as silage in animal feeding.
\end{abstract}

Keywords: Ipomoea batatas, total digestible nutrients, dry mass, neutral and acid detergent fiber, crude protein.

\section{(Recebido para publicação em 14 de setembro de 2011; aceito em 17 de setembro de 2012) (Received on September 14, 2011; accepted on September 17, 2012)}

\begin{abstract}
A batata-doce (Ipomoea batatas) é uma hortaliça tuberosa de fácil cultivo, rústica, de ampla adaptação, com alta tolerância à seca e de baixo custo de produção. É uma das plantas de raiz tuberosa mais cultivadas pelo homem, nas regiões tropicais e subtropicais, e seu cultivo se destina às mais diversas formas de utilização (Peixoto et al., 1999), sendo utilizada na alimentação humana e animal e como matéria-prima nas indústrias de alimento, tecido, papel, cosmético, preparação de adesivos e álcool carburante (Cardoso et al., 2005).

Em nível mundial, é a $7^{\text {a }}$ colocada entre as culturas alimentícias mais importantes (CIP, 2008), sendo colhidas, aproximadamente 136 milhões de toneladas de raízes ao ano, em 9 milhões de hectares, com produtividade média em torno de $15 \mathrm{t} \mathrm{ha}^{-1}$.
\end{abstract}

No Brasil, é a quarta hortaliça mais produzida, com uma produção de aproximadamente 514 mil toneladas, e uma produtividade média de $11,69 \mathrm{t} \mathrm{ha}^{-1} \mathrm{de}$ raízes. A baixa produtividade da cultura da batata-doce no Brasil pode ser atribuída ao desconhecimento de práticas culturais adequadas e, principalmente, à utilização de materiais genéticos obsoletos, suscetíveis a pragas e doenças de solo (Azevedo, 1995). É uma cultura bastante disseminada em todas as regiões brasileiras, de relevância econômica e de ampla aceitação popular, cultivada na maioria das vezes por pequenos produtores rurais (Souza, 2000).

Minas Gerais possui uma área plantada de 1.198 ha, com uma produção de 16.064 toneladas, e produtividade média de 13,41 $\mathrm{t} \mathrm{ha}^{-1}$, valor abaixo da média mundial e acima da média nacional (IBGE, 2008). No Vale do Jequitinhonha, região nordeste do estado de Minas Gerais, o cultivo da batata-doce é amplamente difundido entre os pequenos agricultores, que na grande maioria das vezes a utilizam apenas na alimentação humana, sem aproveitar as ramas e as raízes não comercializáveis ou impróprias para o consumo humano. Os resíduos culturais, tais como ramas e raízes tuberosas não comerciáveis podem ser aproveitados como alimento animal e, de acordo com Figueiredo (1993), chegam a representar mais de $50 \%$ da fitomassa total do cultivo. As ramas, normalmente descartadas, são ricas em amido, açúcares e vitaminas, possuem altas porcentagens de proteína bruta e de digestibilidade (Monteiro et al., 2007) representando um material de alto valor nutritivo, podendo ser forneci- 
das aos animais, verdes ou conservadas na forma de silagem.

Segundo Monteiro et al. (2007) em países como a China e Vietnã, as ramas, empregadas exclusivamente ou em associação às raízes, são largamente utilizadas na alimentação de suínos, seja na forma fresca, ou na forma de silagem. No Brasil, no entanto, a utilização de ramas de batata-doce na alimentação animal é feita em escala bastante limitada e a maior parte das ramas é simplesmente descartada como resíduo inaproveitável. O aproveitamento dos resíduos da cultura para o fornecimento aos animais permite a integração de atividades, contribuindo para o aumento na renda e na melhoria da qualidade de vida do produtor rural. O cultivo de clones que apresentam aptidão agronômica múltipla, ou seja, que apresentam elevadas produtividades de raízes comerciais e de resíduos (ramas + folhas), com elevado potencial para uso na alimentação animal, devem ser preferidos.

Objetivou-se com o presente trabalho selecionar clones de batata-doce adaptados às condições de Diamantina-MG, com potencial de utilização na alimentação animal, na forma de silagem.

\section{MATERIAL E MÉTODOS}

O trabalho foi conduzido no Setor de Olericultura da Universidade Federal dos Vales do Jequitinhonha e Mucuri, em Diamantina (18 $12^{\circ} 01^{\prime \prime} \mathrm{S}, 43^{\circ} 34^{\prime} 20^{\prime \prime} \mathrm{O}$, $1.400 \mathrm{~m}$ de altitude). O solo da área experimental é Quartizarênico Órtico Típico (Embrapa, 2006).

$\mathrm{O}$ delineamento experimental utilizado foi em blocos casualizados, com 11 tratamentos e 4 repetições, com um total de 44 parcelas de $4,5 \mathrm{~m}^{2}$ cada. O espaçamento utilizado foi de 1,0 m entre linhas (camalhões) e 0,30 m entre plantas.

Os clones avaliados fazem parte do banco de germoplasma da UFVJM, sendo: BD-06, BD-38, BD-45, BD-25, BD-31-TO, BD-15, BD-67, BD-42, BD-54, Cambraia e a cultivar Brazlândia Rosada.

A adubação de plantio foi feita com $10 \mathrm{t} \mathrm{ha}^{-1}$ de esterco de curral curtido, $180 \mathrm{~kg} \mathrm{ha}^{-1}$ de fósforo (P), $45 \mathrm{~kg} \mathrm{ha}^{-1} \mathrm{de}$ potássio $(\mathrm{K})$ e $30 \mathrm{~kg} \mathrm{ha}^{-1}$ de nitrogênio $(\mathrm{N})$, de acordo com a análise química do solo e recomendação para a cultura (Filgueira, 2008). O plantio foi realizado utilizando-se ramas selecionadas e padronizadas com oito nós, enterrando-se de 3 a 4 nós, sendo realizado o replantio das ramas até os 20 dias após o plantio.

A irrigação por aspersão foi realizada do plantio até o pegamento das mudas, conforme recomendação de Bernardo et al. (2008).

Após 30 dias do plantio das ramas aplicou-se em cobertura, $45 \mathrm{~kg} \mathrm{ha}^{-1}$ de $\mathrm{K}$ e $30 \mathrm{~kg} \mathrm{ha}^{-1}$ de $\mathrm{N}$.

Durante o período de realização do experimento, as médias da temperatura máxima e mínima foram de 24,4 e $14,7^{\circ} \mathrm{C}$, respectivamente, e da evaporação total foi de $3,1 \mathrm{~mm} \mathrm{dia}^{-1}$.

A colheita foi realizada aos 163 dias após o plantio e a produtividade de massa verde foi determinada por meio da pesagem das ramas colhidas rente ao solo, nas parcelas de cada tratamento, e os resultados foram expressos em $\mathrm{t} \mathrm{ha}^{-1}$.

Para cálculo dos teores de matéria seca, foram retiradas subamostras das ramas recém-colhidas, que foram pesadas, colocadas em sacos de papel e mantidas em estufa com ventilação forçada a $60^{\circ} \mathrm{C}$, até atingir peso constante.

A produtividade de massa seca das ramas foi obtida pelo produto entre a produtividade de massa verde e o teor de matéria seca das ramas e os resultados foram expressos em $\mathrm{t} \mathrm{ha}^{-1}$.

Para a produção das silagens, a parte aérea foi cortada rente ao solo e submetida ao emurchecimento em ambiente coberto com sombrite, durante quatro dias. As ramas foram picadas em um desintegrador com tamanhos de partículas em torno de $2 \mathrm{~cm}$ e ensiladas em 24 silos de PVC, com $50 \mathrm{~cm}$ de altura e 10 $\mathrm{cm}$ de diâmetro, providos com válvula de Bünsen e lacrados com fita adesiva. A abertura dos silos foi realizada aos 46 dias após a ensilagem, sendo retiradas amostras de silagem da porção central de cada silo, que foram congeladas para a realização das análises.

O teor de proteína bruta da silagem foi determinado por destilação em aparelho Kjeldahl (semimicro), sendo seus valores expressos em porcentagem da matéria seca (Silva \& Queiroz, 2002).

As fibras em detergente ácido (FDA) e detergente neutro (FDN) foram determinadas por meio do método proposto por Van Soest (1967) e descrito por Silva \& Queiroz (2002).

Os nutrientes digestíveis totais (NDT) foram obtidos conforme recomendações de Sniffen et al. (1992), sendo seus valores expressos em porcentagem de matéria seca.

$\mathrm{O} \mathrm{pH}$ foi determinado por potenciometria em eletrodo de vidro, segundo técnica da AOAC (1990).

Os minerais cálcio, fósforo e sódio foram determinados por espectrofotometria de absorção atômica com chama de acetileno, segundo metodologia estabelecida por Sarruge \& Haag (1974) e Fiske \& Subbarow (1925).

Os dados foram submetidos à análise de variância e as médias dos tratamentos foram comparadas utilizando-se o teste de Scott \& Knott (1974) $(\mathrm{p}<0,05)$. Para análise dos dados foi utilizado o programa computacional SISVAR (Ferreira, 2011).

\section{RESULTADOS E DISCUSSÃO}

Não foram observadas diferenças significativas pelo teste $\mathrm{F}$ para as características produtividade de massa verde (PMV) e produtividade de massa seca (PMS) das ramas. Já para a característica teor de matéria seca (MS) nas ramas houve diferença significativa pelo teste $\mathrm{F}(\mathrm{p}<0,05)$.

Apesar de não haver diferença significativa entre os clones para PMV e PMS, observa-se grande amplitude nos resultados, com a produtividade de matéria verde (PMV) variando de 13,84 tha ${ }^{-1}$, obtida com o clone BD-42, a 23,90 t ha ${ }^{-1}$ registrada para o clone BD-45, e a PMS de 3,05 tha- (BD-06) a 4,95 $\mathrm{tha}^{-1}$ (BD-45). A PMV média foi de 19,62 $\mathrm{t}$ $\mathrm{ha}^{-1}$, entretanto, apenas os clones BD-42, BD-67 e BD-06 proporcionaram PMV de ramas inferior a $20 \mathrm{t} \mathrm{ha}^{-1}$ (Tabela 1). Aguiar et al. (2009) avaliaram 11 clones de batata-doce em Diamantina, e obtiveram PMV de ramas bem inferior, variando entre 4,46 e 12,12 $\mathrm{t} \mathrm{ha}^{-1}$, enquanto Viana et al. (2011) registraram PMV de 18,52 a 64,62t ha-1 avaliando 
Tabela 1. Produtividade de massa verde (PMV), teor de matéria seca (MS) e produtividade de massa seca (PMS) das ramas de clones de batata-doce (productivity of fresh mass (PMV), dry matter (MS) and yield of dry matter (PMS) of sweet potato vines). Diamantina, UFVJM, 2011.

\begin{tabular}{lccc}
\hline Clones & PMV $^{\text {ns }}\left(\mathbf{t ~ h a}^{-1}\right)$ & $\mathbf{M S}^{*} \mathbf{( \% )}$ & $\mathbf{P M S}^{\mathbf{n s}}\left(\mathbf{t ~ h a}^{-\mathbf{1}}\right)$ \\
\hline BD-45 & 23,90 & $20,77 \mathrm{~b}$ & 4,95 \\
BD-25 & 21,58 & $22,35 \mathrm{a}$ & 4,82 \\
BD-31-TO & 21,55 & $20,53 \mathrm{~b}$ & 4,37 \\
BD-38 & 21,09 & $20,68 \mathrm{~b}$ & 4,20 \\
BD-15 & 20,97 & $21,25 \mathrm{~b}$ & 4,47 \\
BD-54 & 20,51 & $24,31 \mathrm{a}$ & 4,93 \\
BD-67 & 15,90 & $21,81 \mathrm{a}$ & 3,39 \\
BD-06 & 14,97 & $20,45 \mathrm{~b}$ & 3,05 \\
BD-42 & 13,84 & $24,16 \mathrm{a}$ & 3,36 \\
Cambraia & 20,54 & $18,56 \mathrm{~b}$ & 3,85 \\
Brazlândia Rosada & 20,99 & $22,68 \mathrm{a}$ & 4,77 \\
\hline Média & 19,62 & 21,59 & 4,20 \\
CV (\%) & 39,95 & 9,43 & 38,29 \\
\hline
\end{tabular}

${ }^{*} \mathrm{e}^{\mathrm{ns}}=$ significativo e não significativo pelo teste $\mathrm{F}$, respectivamente. Médias seguidas de mesma letra na coluna não diferem entre si, pelo teste de Scott \& Knott (1974) em nível de 5\% de significância ( ${ }^{*}$ and ${ }^{\text {ns }}$ significant and not significant for the $\mathrm{F}$ test, respectively. Means followed by same letter in column do not differ by Scott \& Knott (1974) test at 5\% of significance).

oito clones colhidos em três idades de colheita, 120, 150 e 180 dias. Andrade Júnior et al. (2009) obtiveram com doze clones, PMV de 3,81 a 11,76 tha-1. Massaroto (2008) registrou produtividade de massa verde de 50,0 $\mathrm{t} \mathrm{ha}^{-1}$, em trabalho realizado em Lavras-MG, enquanto Cardoso et al. (2005), avaliando clones de batata-doce em Vitória da Conquista, encontraram produtividade de massa verde entre 1,4 e 14,1 $\mathrm{t} \mathrm{ha}^{-1}$.

Houve diferença entre os clones para os teores de matéria seca nas ramas, sendo que BD-25, BD-54, BD-67, BD42 e Brazlândia Rosada, sem diferirem entre si, superaram os demais (Tabela 1). O teor de matéria seca influi grandemente sobre a natureza da fermentação e conservação da massa ensilada; Baixos teores são prejudiciais, pois, além de promoverem fermentação indesejável, segundo Euclides (1995), podem também limitar o consumo de forragem pelos animais. Considerando que as forrageiras mais indicadas para ensilagem devem apresentar em torno de $30 \%$ de MS (Tomich et al., 2004), nenhum dos clones atenderia a exigência, sugerindo a necessidade da adoção de técnicas que promovam redução nos teores de umidade, como o emurchecimento. Viana et al
(2011) observaram que na colheita aos 180 dias, as ramas dos clones avaliados (BD-08, BD-15, BD-25, BD-38, BD45, BD-31-TO e cultivares Brazlândia Rosada e Princesa) apresentaram os maiores teores de matéria seca, com valor médio de $19,62 \%$. Segundo os autores, os teores de matéria seca nas ramas aumentam com o ciclo da cultura. Em ensaio realizado por Massaroto (2008), avaliando silagens de 24 clones de batata-doce, observaram-se teores de MS nas ramas variando de 11,5 a 17,5\% e nas silagens de 17,0 a $26,3 \%$, sugerindo que houve grande perda de efluentes das silagens, devido aos baixos teores de matéria seca das ramas. Aguiar et al. (2009) registraram teores bem superiores de MS, na faixa de 25,45 a $39,90 \%$.

A produtividade de matéria seca (PMS) de ramas, em tha-1 ${ }^{-1}$ foi estatisticamente semelhante entre os clones, e variou de 3,05 a $4,95 \mathrm{t} \mathrm{ha}^{-1}$. A PMS média foi de 4,20 tha $\mathrm{t}^{-1}$, e os clones BD-54, BD-25, BD-45 e a cv. Brazlândia rosada proporcionaram PMS acima de $4,5 \mathrm{tha}^{-1}$. Massaroto (2008) encontrou PMS variando de 1,0 a 7,2 tha $^{-1}$, enquanto Viana et al. (2011), avaliando a produção de ramas de seis clones de batata-doce do banco de germoplasma da UFVJM e duas cultivares da Embrapa Hortaliças, em diferentes épocas de colheita, em Diamantina-MG, registraram produtividades de MS entre 3,69 e 9,48 $\mathrm{t} \mathrm{ha}^{-1}$, com produtividade média de $6,02 \mathrm{t} \mathrm{ha}^{-1}$.

Analisando as silagens das ramas de batata-doce observou-se diferenças significativas pelo teste $\mathrm{F}$ para as características $\mathrm{pH}$, teor de matéria seca, fibra detergente neutro, fibra detergente ácido, nutrientes digestíveis totais, fósforo e sódio. Para os teores de proteína bruta e cálcio não foram observadas diferença significativa entre os clones estudados (Tabela 2).

Os valores de $\mathrm{pH}$ das silagens variaram de 4,17 a 4,59, e segundo MacDonald (1981), o ideal é que os valores se situem na faixa de 3,8 a 4,2, indicando um padrão de fermentação adequado. O clone BD-15 foi o único que proporcionou silagens com $\mathrm{pH}$ considerado adequado, 4,17 (Tabela 2). Monteiro et al. (2007), avaliando silagens de cultivares e clones de batata-doce, encontraram valores de pH entre 3,8 e 4,5. O pH é um dos parâmetros utilizados para avaliar a qualidade do processo de ensilagem e é um dos fatores capazes de determinar o crescimento e a sobrevivência de microrganismos num alimento. $\mathrm{O}$ grupo de bactérias anaeróbias (Clostridium) tem efeito pronunciado na qualidade da silagem se os valores de $\mathrm{pH}$ não forem suficientemente baixos para inibir o seu desenvolvimento (Reis \& Rosa, 2001). Entretanto, Cherney \& Cherney (2003) consideram o pH como um bom indicador da qualidade de fermentação nas silagens com baixo teor de MS, não considerando como adequado para silagens com alto teor de MS.

As silagens apresentaram teores de MS entre 17,27 e $24,10 \%$, e os clones BD-45, BD-31 TO e cv. Cambraia apresentaram os mais baixos teores, inferiores a $21 \%$. Os teores de MS obtidos nas silagens (Tabela 2) em alguns casos foram superiores aos obtidos nas ramas, em outros foram semelhantes (BD-45 e BD-42) ou até mesmo inferiores (BD31-TO e BD-54) (Tabela 1). Teores de MS mais elevados nas silagens eram esperados, haja vista que o material foi submetido ao emurchecimento antes da ensilagem. Além disso, segundo 
Tabela 2. Valores do potencial hidrogeniônico $(\mathrm{pH})$ e teores de matéria seca (MS), proteína bruta (PB), fibra detergente neutro (FDN), fibra detergente ácido (FDA), nutrientes digestíveis totais (NDT), fósforo (P), cálcio (Ca) e sódio (Na) em silagem de ramas de batata-doce (values of the hydrogenionic potential (pH) and dry matter (MS), crude protein (PB), neutral detergent fiber (FDN), acid detergent fiber (FDA), total digestible nutrients (NDT), phosphorus (P), calcium (Ca) and sodium (Na) in silage of sweet potato vines). Diamantina, UFVJM, 2011.

\begin{tabular}{lccccccccc}
\hline Clones & $\mathbf{p H}^{* *}$ & $\mathbf{M S}^{*}(\mathbf{\%})$ & $\mathbf{P B}^{\text {ns }}(\mathbf{\%})$ & $\mathbf{F D N}^{* *}(\mathbf{\%})$ & $\mathbf{F D A}^{* * *}(\mathbf{\%})$ & $\mathbf{N D T}^{* *}(\mathbf{\%})$ & $\mathbf{P}^{* * *}(\%)$ & $\mathbf{C a}^{\text {ns }}(\mathbf{\%})$ & $\mathbf{N a}^{* * *}(\mathbf{p p m})$ \\
\hline BD-45 & $4,51 \mathrm{a}$ & $20,76 \mathrm{~b}$ & 9,66 & $36,10 \mathrm{~b}$ & $33,40 \mathrm{a}$ & $65,95 \mathrm{a}$ & $0,37 \mathrm{~b}$ & 1,08 & $64,40 \mathrm{c}$ \\
BD-25 & $4,56 \mathrm{a}$ & $23,37 \mathrm{a}$ & 12,33 & $34,57 \mathrm{~b}$ & $30,95 \mathrm{~b}$ & $66,17 \mathrm{a}$ & $0,31 \mathrm{c}$ & 0,96 & $87,70 \mathrm{~b}$ \\
BD-31TO & $4,41 \mathrm{a}$ & $17,27 \mathrm{~b}$ & 11,37 & $31,98 \mathrm{~b}$ & $29,65 \mathrm{~b}$ & $66,98 \mathrm{a}$ & $0,37 \mathrm{~b}$ & 1,07 & $326,70 \mathrm{a}$ \\
BD-38 & $4,29 \mathrm{~b}$ & $22,54 \mathrm{a}$ & 12,59 & $35,03 \mathrm{~b}$ & $31,10 \mathrm{~b}$ & $66,07 \mathrm{a}$ & $0,30 \mathrm{c}$ & 1,02 & $62,30 \mathrm{c}$ \\
BD-15 & $4,17 \mathrm{~b}$ & $22,88 \mathrm{a}$ & 11,11 & $36,55 \mathrm{~b}$ & $34,85 \mathrm{a}$ & $63,46 \mathrm{~b}$ & $0,32 \mathrm{c}$ & 0,99 & $64,15 \mathrm{c}$ \\
BD-54 & $4,48 \mathrm{a}$ & $22,48 \mathrm{a}$ & 11,76 & $39,68 \mathrm{a}$ & $35,45 \mathrm{a}$ & $62,90 \mathrm{~b}$ & $0,34 \mathrm{c}$ & 1,11 & $48,65 \mathrm{c}$ \\
BD-67 & $4,27 \mathrm{~b}$ & $22,31 \mathrm{a}$ & 11,19 & $39,45 \mathrm{a}$ & $35,30 \mathrm{a}$ & $63,13 \mathrm{~b}$ & $0,41 \mathrm{a}$ & 1,21 & $82,55 \mathrm{~b}$ \\
BD-06 & $4,59 \mathrm{a}$ & $23,25 \mathrm{a}$ & 12,27 & $37,85 \mathrm{a}$ & $35,35 \mathrm{a}$ & $63,09 \mathrm{~b}$ & $0,31 \mathrm{c}$ & 0,95 & $83,90 \mathrm{~b}$ \\
BD-42 & $4,29 \mathrm{~b}$ & $24,10 \mathrm{a}$ & 11,06 & $35,05 \mathrm{~b}$ & $29,90 \mathrm{~b}$ & $66,91 \mathrm{a}$ & $0,29 \mathrm{c}$ & 0,89 & $54,45 \mathrm{c}$ \\
Cambraia & $4,54 \mathrm{a}$ & $19,39 \mathrm{~b}$ & 12,02 & $36,60 \mathrm{~b}$ & $31,50 \mathrm{~b}$ & $66,19 \mathrm{a}$ & $0,41 \mathrm{a}$ & 1,15 & $58,20 \mathrm{c}$ \\
Braz. Ros. & $4,38 \mathrm{~b}$ & $23,95 \mathrm{a}$ & 12,06 & $39,48 \mathrm{a}$ & $33,30 \mathrm{a}$ & $64,53 \mathrm{~b}$ & $0,44 \mathrm{a}$ & 0,80 & $70,75 \mathrm{c}$ \\
\hline Média & 4,41 & 22,03 & 11,59 & 36,58 & 32,80 & 65,04 & 0,35 & 1,02 & 91,25 \\
CV (\%) & 2,36 & 11,11 & 10,70 & 6,07 & 5,64 & 1,51 & 4,60 & 31,43 & 10,17 \\
\hline
\end{tabular}

${ }^{* *},{ }^{*} \mathrm{e}^{\mathrm{ns}}=$ significativo e não significativo pelo teste $\mathrm{F}$, respectivamente. Médias seguidas pela mesma letra minúscula nas colunas não diferem entre si pelo teste de Scott \& Knott (1974) em nível de 5\% de significância $\left({ }^{* *},{ }^{*}\right.$ and ${ }^{\text {ns }}=$ significant and not significant for the F test, respectively. Means followed by same letter in column do not differ by Scott \& Knott (1974) test at 5\% of significance).

McDonald et al. (1991), a redução nos teores de MS com a ensilagem pode ser atribuída à diminuição do conteúdo celular durante o processo fermentativo, principalmente de carboidratos solúveis (Woolford, 1984) e à perda de MS por meio de efluentes. Viana et al. (2011) e Aguiar et al. (2009) registraram em silagens de ramas de batata-doce teores médios de $20,40 \%$ e $30,79 \%$ de MS, respectivamente, enquanto no presente estudo esse valor foi de $22,03 \%$.

Os teores de PB variaram de 9,66 a $12,59 \%$, com valor médio de $11,59 \%$. Considerando que para as atividades normais das bactérias ruminais são necessários de 6 a $8 \%$ de PB (Mertens, 1994), todas as cultivares atenderiam a exigência. Viana et al. (2011) também não observaram diferenças no teor de $\mathrm{PB} \%$ das silagens de ramas de clones de batata-doce, cujos teores variaram de 9,63 a $12,07 \%$, com média de $10,93 \%$. Monteiro et al. (2007) registraram teores semelhantes, entre 9,64 e 13,16\% de PB.

Quanto aos valores de FDN (Tabela 2), os clones BD-54, BD-67, BD-06 e B. Rosada apresentaram teores mais elevados que os demais, mas sempre inferiores a $40 \%$ da MS. Resultados que contrastam com os de Viana et al. (2011), que encontraram teores de FDN superiores, variando de 43,83 a $47,57 \%$ e de Monteiro et al. (2007), que verificaram teores de FDN entre 37,86 e $58,18 \%$. O teor de FDN é um importante parâmetro que define a qualidade da forragem, sendo que valores acima de $60 \%$ correlacionam-se negativamente com o consumo voluntário dos animais (Van Soest, 1994).

Os valores de FDA variaram de 29,65 a $35,45 \%$ (Tabela 2). Os clones BD-25, BD-31-TO, BD-38, BD-42 e cv Cambraia apresentaram teores mais baixos de fibra. Os valores de FDN e FDA fazem parte da fração fibrosa do volumoso e valores muito altos podem ser prejudiciais, pois dificultam a digestão pelos microrganismos no trato digestível dos animais, diminuindo a qualidade nutricional. Alguns clones de batata-doce apresentaram valores de FDA próximos aos valores encontrados para silagem de milho que, segundo Valadares Filho et al. (2002), apresenta, em média, 30,1\%. Viana et al. (2011), avaliando silagens de clones de batata-doce, encontraram valores de FDA variando de 36,50 a $39,43 \%$, enquanto Monteiro et al. (2007) registraram teores mais elevados, entre 34,33 e $50,76 \%$ de FDA.

A energia é o primeiro fator limitante à vida e às funções produtivas dos animais, e sua determinação nos alimentos é de extrema importância para o perfeito atendimento de suas exigências. Os clones BD-45, BD-31 TO, BD-25, BD-38, BD-42 e Cambraia destacaram-se com teores de NDT superiores a $65 \%$ da MS (Tabela 2), valores semelhantes aos obtidos com silagem de milho. O teor médio registrado foi de $65,04 \%$, valor superior ao encontrado por Viana et al. (2011) que, avaliando silagens de diferentes clones de batata-doce, obtiveram teor de NDT médio de $60,95 \%$.

Os teores de $\mathrm{P}$ variaram de $0,29 \%$ a $0,44 \%$, (Tabela 2 ), sendo os valores mais elevados obtidos com o clone BD-67, cv. Cambraia e Brazlândia Rosada, e os valores inferiores obtidos com BD-25, BD-38, BD-15, BD-54, BD-06 BD-42. Para o cálcio, não foi observada diferença significativa entre os clones, com valor médio de $1,02 \%$ na MS. Em relação ao sódio, o clone BD-31 TO apresentou valor muito superior aos demais, 326,70 ppm, enquanto os clones BD-25, BD-67 e BD-06 apresentaram valores intermediários. Não foram encontrados na literatura valores para os teores de $\mathrm{P}, \mathrm{Ca}$ e $\mathrm{Na}$ em silagens de ramas de batata-doce. Para silagens de ramas de cultivares de mandioca, Azevedo et al. 
(2006), obtiveram valores de $0,36 \%$ de $\mathrm{P}, 0,98$ a $1,06 \%$ de $\mathrm{Ca}$, e valores de sódio entre 0,005 e $0,012 \%$.

Pode-se concluir que as silagens produzidas caracterizam-se como volumosos de boa qualidade, apresentando valores médios de $11,59 \%$ de proteína bruta, baixos teores de fibra e teores de NDT superiores a $62,90 \%$, comprovando o potencial de utilização das ramas de batata-doce na forma de silagem.

\section{AGRADECIMENTOS}

À FAPEMIG (Fundação de Amparo à Pesquisa do Estado de Minas Gerais), CNPq (Conselho Nacional de Desenvolvimento Científico e Tecnológico) e CAPES (Coordenação de Aperfeiçoamento de Pessoal de Nível Superior) pelo auxílio financeiro e concessão de bolsas de estudos.

\section{REFERÊNCIAS}

AGUIAR EF; LEMOS VT; PEDROSA CE; VIANA DS; CASTRO JO; AZEVEDO AM. 2009. Produtividade e teor de matéria seca de ramas e silagem de clones de batata doce no Alto Jequitinhonha. In: ZOOTEC - Visão estratégica do Agronegócio. Anais... Águas de Lindóia: FZEA/USP. Disponível em http://www.abz.org.br/publicacoes-tecnicas/ anais-zootec/artigos-cientificos/forragiculturapastagens/21334.html. Acessado em 18 de julho de 2011.

ANDRADE JÚNIOR VC; VIANA DJS; FERNANDES JSC; FIGUEIREDO JA; NUNES UR; NEIVA IP. 2009. Selection of sweet potato clones for the region Alto Vale do Jequitinhonha. Horticultura Brasileira 27: 389-393.

AOAC. ASSOCIATION OF OFFICIAL ANALYTICAL CHEMISTS. 1990. Official methods of analysis of the Association. Washington.1140p.

AZEVEDO EB; NÖRNBERG JL; KESSLER JD; BRÜNING G; DAVID DB; FALKENBERG JR; CHIELLE ZG. 2006. Silagem da parte aérea de cultivares de mandioca.Ciência Rural 36: 1902-1908.

AZEVEDO SM. 1995. Avaliação de familias de meio-irmãos de batata-doce (Ipomoea batatas (L.) LAM.) quanto à resistência aos nematóides do gênero Meloidogyne $e$ insetos de solo. Lavras: UFLA. 61p (Tese mestrado).

BERNARDO S; SOARES AA; MANTOVANI EC. 2008. Manual de irrigação. Viçosa: UFV. 625 p.

CARDOSO AD; VIANA AES; RAMOS PAS; MATSUMOTO SN; AMARAL CLF; SEDIYAMA T; MORAIS OM. 2005. Avaliação de clones de batata-doce em Vitória da Conquista. Horticultura Brasileira 23: 911-914.

CHERNEY JH; CHERNEY DJR. 2003. Assessing Silage Quality. In: BUXTON DR; MUCK R; HARRISON J (eds) Silage science and technology. Madison: American Society of Agronomy p.141-198.

CIP (CENTRO INTERNACIONAL DE LA PAPA). 2008. Sweetpotato. Disponível em: $<$ http//www.cipotato.org $>$. Acesso em: 29 de setembro de 2008.

EMBRAPA. 2006. CNPH - Centro Nacional de Pesquisa de Hortaliças. Embrapa Hortaliças. Disponível em: www.cnph.embrapa.br. 15 de abril de 2006.

EUCLIDES VPB. 1995. Valor alimentício de espécies forrageiras do gênero Panicum. In: SIMPÓSIO SOBRE MANEJO DA PASTAGEM, 12. Anais... Piracicaba: FEALQ. p. 245-276.

FERREIRADF. 2011. Sisvar: a computer statistical analysis system. Ciência e Agrotecnologia 35: 1039-1042.

FIGUEIREDO AF. 1993. Armazenamento de ramas, tipos de estacas, profundidade de plantio e análise do crescimento de batata-doce [Ipomoea batatas (L.) Lam.]. Viçosa: UFV. 127 p. (Tese Doutorado).

FILGUEIRA FAR. 2008. Novo manual de olericultura. Viçosa: UFV. 421p.

FISKE CH; SUBBAROW Y. 1925. The calorimetric determination of phosphorus. Journal of Biological Chemistry. Bethesda, 66: 375-400.

IBGE. 2008. Produção agrícola mundial. Disponível em: http://www.ibge.gov.br/home/ mapa_site/mapa_site.php\#indicadores. Acesso em: 10 de agosto de 2008.

McDONALD P; HENDERSON AR; HERON SJE. 1991. The biochemistry of silage. New York: Marlow - Chalcombe Publications. 340p.

McDONALD, P. The biochemistry of silage. New York: John Wiley, 1981. 207p.

MASSAROTO JA. 2008. Características agronômicas e produção de silagem de clones de batata-doce. Lavras: UFLA.85p (Tese doutorado).

MERTENS DR. 1994. Regulation of forage intake. In: Forage quality, evaluation and utilization. Proceedings... Madison: American Society of
Agronomy. p. 450-493.

MONTEIRO AB; MASSAROTO JA; GASPARINO CF; SILVA RR; GOMES LAA; MALUF WR; FILHO JCS. 2007. Silagens de cultivares e clones de batata doce para alimentação animal visando sustentabilidade da produção agrícola familiar. Revista Brasileira de Agroecologia 2: 978-981.

PEIXOTO JR; SANTOS LC; RODRIGUES FA; JULATTI FC; LYRA JRM. 1999. Seleção de clones de batata-doce resistentes a insetos de solo. Pesquisa Agropecuária Brasileira 34: 385-389.

REIS RA; ROSA B. 2001. Suplementação volumosa: conservação do excedente das pastagens. In: SIMPÓSIO SOBRE MANEJO DA PASTAGEM, 18. Anais... Piracicaba: FEALQ. p.193-232.

SARRUGE JR; HAAG HP. 1974. Análise química em plantas. Piracicaba: ESALQ. 55p.

SILVA DJ; QUEIROZ AC. 2002. Análise de alimentos: métodos químicos e biológicos. Viçosa: UFV. 235p.

SNIFFEN CJ; O'CONNOR JD; VAN SOEST PJ; FOX DG; RUSSELL JB. 1992. A net carbohydrate and protein system for evaluating cattle diets: II. Carbohydrate and protein availability. Journal of Animal Science. 70: 3562-3577.

SOUZA AB. 2000. Avaliação de cultivares de batata-doce quanto a atributos agronômicos desejáveis. Ciência e Agrotecnologia 24: 841-845.

TOMICH TR.; PEREIRA L GR; GONÇALVES LC. 2004. Alimentos volumosos para o período seco - I: Silagem de girassol. Corumbá: EMBRAPA Pantanal. 30p. Disponível em: http://www.cpap.embrapa.br/publicacoes. Acessado em: 16 de março de 2010.

VALADARES FILHO SC; ROCHA JÚNIOR VR; CAPPELLE ER. 2002. Tabelas Brasileiras de composição de alimentos para bovinos. Viçosa: UFV - DZO. 297p.

VAN SOEST PJ. 1994. Nutritional ecology of the ruminant. Ithaca: Cornell University Press. 446 p.

VAN SOEST PJ. 1967. Use of detergents in the analyses of fibrous feeds. 2. A rapid method for the determination of fiber and lignin. Journal Association Official Analytical Chemists 46: 829-835.

VIANA, DJS; ANDRADE JÚNIOR VC; RIBEIRO KG; PINTO NAVD; NEIVA IP; FIGUEIREDO JA; LEMOS VT; PEDROSA CE; AZEVEDO AM. 2011. Potencial de silagens de ramas de batata-doce para alimentação animal. Ciência Rural 41: 14661471.

WOOLFORD MK. 1984. The silage fermentation. New York: Marcel Dekker. 350p. 